\title{
Electroanalysis of Imidacloprid Insecticide in River Waters Using Functionalized Multi-Walled Carbon Nanotubes Modified Glassy Carbon Electrode
}

\author{
Wyslley Douglas A. Paiva, ${ }^{1}$ Thiago Mielle B. F. Oliveira, ${ }^{1,2}$ Camila P. Sousa, ${ }^{3}$ \\ Pedro de Lima Neto, ${ }^{3}$ Adriana N. Correia, ${ }^{3}$ Simone Morais, ${ }^{4}$ Djalma R. Silva, ${ }^{5}$ \\ and Suely Souza Leal Castro 1,z \\ ${ }^{1}$ Faculdade de Ciências Exatas e Naturais, Universidade do Estado do Rio Grande do Norte, Mossoró, RN 59625-620, \\ Brazil \\ ${ }^{2}$ Centro de Ciência e Tecnologia, Universidade Federal do Cariri, Cidade Universitária, Juazeiro do Norte, \\ CE 63048-080, Brazil \\ ${ }^{3}$ Centro de Ciências, Universidade Federal do Ceará, Fortaleza, CE 60455-760, Brazil \\ ${ }^{4}$ REQUIMTE-LAQV, Instituto Superior de Engenharia do Porto, Instituto Politécnico do Porto, 4200-072 Porto, \\ Portugal \\ ${ }^{5}$ Instituto de Química, Universidade Federal do Rio Grande do Norte, Natal, RN 59078-970, Brazil
}

\begin{abstract}
In this work, a functionalized multi-walled carbon nanotubes modified glassy carbon electrode (GCE/MWCNT-f) was optimized for the direct determination of imidacloprid (IMC) insecticide in river water. The functionalized material was characterized by infrared spectroscopy with Fourier transform (FTIR) and the modified electrode by scanning electron microscopy (SEM) and cyclic voltammetry (CV). Results revealed that the GCE/MWCNT-f effectively increased the response toward IMC reduction by enhancing the reduction peak current and decreasing the peak potential in comparison with the bare electrode. After optimizing the electroanalytical conditions, the GCE/MWCNT-f showed a linear voltammetric response at concentration ranging from $2.40 \times 10^{-7}$ to $3.50 \times 10^{-6} \mathrm{~mol} \mathrm{~L}^{-1}$, with detection and quantification limits of $4.15 \times 10^{-7} \mathrm{~mol} \mathrm{~L}^{-1}$ and $1.38 \times 10^{-6} \mathrm{~mol} \mathrm{~L}^{-1}$, respectively. The recovery rate of IMC in spiked river water samples varied from $90-95 \%$. Thus, this sensor can be a promising tool for the analysis and monitoring of IMC in complex environmental matrices.
\end{abstract}

In the last years, the development of reliable, simple, fast and low cost analytical procedures for determination of contaminants, such as crop protection agents, has been increasing. ${ }^{1-3}$ Pesticides are applied to soil or sprayed over agricultural crops and then released into the environment with the accumulation of these compounds in water. Since some of them are chemically stable and resistant to biological treatment, they may cause risks of long-term toxicity to environmental and human health. ${ }^{4,5}$

Neonicotinoids represent one of the most important classes of insecticides because they are potent agonists of acetylcholine, suppressing the acetylcholinesterase transmission by binding to the postsynaptic nicotinic receptors in the central nervous system of the insects. The accumulation of acetylcholine results in the paralysis and death of the insects. Due to their high efficiency, the use of these insecticides in agriculture and, as a consequence, their presence in the environment has been increasing. ${ }^{6}$ Imidacloprid (IMC; [1(6-chloro-3-pyridylmethyl)-N-nitroimidazolidin-2-ylideneamine]) (Figure 1), the first member of the neonicotinoid family, has high water solubility $\left(0.58 \mathrm{~g} \mathrm{~L}^{-1}\right)$ and stability (more than 30 days), accounting for approximately $41.5 \%$ of the whole neonicotinoid market. ${ }^{6,7}$ Thus, monitoring of this compound in watercourses is required to reduce negative environmental and health impacts, to help selecting the adequate use of the waters, besides supporting the selection of the appropriate type of water treatment to be carried out before water distribution to the population.

Various analytical methods have been proposed for the determination of IMC, such as high-performance liquid chromatography, ${ }^{8,9}$ gas chromatography, ${ }^{1,10}$ fluorimetry, ${ }^{11}$ enzyme-linked immunoassay, ${ }^{12}$ Fourier transform infrared spectroscopy, ${ }^{13}$ colorimetry ${ }^{14}$ and electroanalytical methods. ${ }^{3,15-23}$ Due to the wide applicability and high efficiency, liquid chromatography techniques have been widely used. ${ }^{8,9}$ However, these methods require high amounts of organic solvents, expensive equipment, experienced technicians, time-consuming preparation and detection procedures and are not suitable for real-time detection. In contrast, electrochemical methods require low cost instruments, simple sample preparation procedure (when necessary), adaptability for field analysis or on-line monitoring, and minimum use of toxic organic solvents. Moreover, electroanalytical techniques are characterized by presenting low limits of detection, high analyte selectivity and versatility. The modification of the electrode-solution interface also allows to obtain better responses when compared to those obtained with conventional electrodes, such as electrocatalysis of redox reactions. ${ }^{24,25}$ Thus, and because IMC exhibits electroactivity, research involving the development of electroanalytical methods for the determination of this compound in different real samples has shown a significant growth. ${ }^{3,15-23}$ Different IMC sensors have been proposed, such as modified carbon-based electrodes (Table I). ${ }^{3,15,17-19,22,23}$ At the nanoscale, carbon is a unique and very versatile element. Carbon nanotubes (CNTs) have high surface area, allowing amplification of the analytical signal, and electrocatalytic properties, which are directly related to the electronic transport in the material. ${ }^{26,27}$ Electron transport can occur ballistically in the basal plane, but its velocity can be increased with the presence of functional groups distributed in $\mathrm{CNTs},{ }^{28}$ which can be inserted by treatment in oxidizing medium; thus, the electronic properties of these nanomaterials, as well as the mechanical ones, can be considerably enhanced for sensors development. In addition, the incorporation of carboxylic groups by oxidative treatment in medium to strong acids ${ }^{29}$ for example, provides greater hydrophilic properties, facilitating their dispersion in water. ${ }^{30}$

To our knowledge, there are no studies available in the literature on the use of multi-walled carbon nanotubes (MWCNT) modified glassy carbon electrode (GCE) for the direct determination of IMC. In this work, we report an easy method of functionalization of MWCNT in strong acid medium (MWCNT-f) and its use as hydrophilic surface for the detection of IMC insecticide. Infrared spectroscopy with Fourier Transform (FTIR) was used to characterize the functionalized material, while cyclic voltammetry $(\mathrm{CV})$ and scanning electron microscopy (SEM) were applied to characterize the modified electrode. Moreover, the applicability and accuracy of the developed sensor was assessed by determining IMC in river water samples.

\section{Materials and Methods}

Chemicals and solutions.-Analytical grade reagents, without further purification, were employed in all experiments. The MWCNT, 
Table I. Review of the reported analytical parameters for IMC determination using carbon-based electrodes.

\begin{tabular}{|c|c|c|c|c|}
\hline Electrode & Method & Linear range $\left(\mu \mathrm{mol} \mathrm{L}{ }^{-1}\right)$ & Detection limit $\left(\mu \mathrm{mol} \mathrm{L}^{-1}\right)$ & Reference \\
\hline $\mathrm{PB} / \mathrm{MWNT} / \mathrm{GCE}$ & LSV & $0.113-29.4$ & 0.05 & 15 \\
\hline CPE & DPV & $6.7-117.4$ & 2.04 & 16 \\
\hline $\mathrm{CuPC} / \mathrm{CCE}$ & DPV & $0.67-17$ and $17-93$ & 0.28 & 17 \\
\hline$\beta-\mathrm{CDP} / \mathrm{rGO} / \mathrm{GCE}$ & $\mathrm{CV}$ & $1-150$ & 0.1 & 18 \\
\hline$\beta-\mathrm{CDP} / \mathrm{rGO} / \mathrm{GCE}$ & DPV & $0.05-15$ and $20-150$ & 0.02 & 18 \\
\hline MWCNTs/Asp/GCE & LSV & $0.06-8$ and $8-60$ & 0.045 & 19 \\
\hline BDD & SWV & $30-200$ & 8.6 & 21 \\
\hline IL/CCE & DPV & $0.05-7$ & 0.031 & 22 \\
\hline AgNDs/GNs/GCE & DPV & $1-100$ & 0.814 & 23 \\
\hline GCE & $\mathrm{CV}$ & $10.9-1956$ & 30.1 & 43 \\
\hline GCE/MWCNT- $f$ & $\mathrm{CV}$ & $0.24-3.5$ & 0.41 & This work \\
\hline
\end{tabular}

PB/MWNT/GCE: Prussian blue and multi-walled carbon nanotubes modified glassy carbon electrode; CPE: carbon paste electrode; CuPC/CCE: Copper(II) phthalocyanine modified carbon ceramic electrode; $\beta$-CDP/rGO/GCE: $\beta$-Cyclodextrin polymer and Reduced-graphene oxide modified glassy carbon electrode; MWCNTs/Asp/GCE: Poly(aspartic acid) and multi-walled carbon nanotubes modified glassy carbon electrode; BDD: boron doped diamond; IL/CCE: Ionic liquid modified carbon ceramic electrode; AgNDs/GNs/GCE: Ag nanodendrimers and graphene nanosheets modified glassy carbon electrode.

of about $10 \mathrm{~nm}$ in diameter, $1.5 \mu \mathrm{m}$ in length and purity greater than 95\% were purchased from DropSens (Spain); IMC of $99.5 \%$ purity was supplied by Chem Service (USA); potassium chloride (99.5\%) by Merck (Germany) and ethyl alcohol and hydrochloric, sulfuric and nitric acids by Vetec (Brazil). All solutions were prepared with ultrapure water (resistivity $\geq 18 \mathrm{M} \Omega \mathrm{cm}^{-1}$ ).

Apparatus.-The voltammetric measurements were performed using an electrochemical system composed of a potentiostat/galvanostat model $\mu$ Autolab III (Metrohm Pensalab) controlled by Nova 1.10 software, a conventional electrochemical cell $(5 \mathrm{~mL})$ with a threeelectrode system, consisting of a bare or modified glassy carbon electrode ( $3 \mathrm{~mm}$ diameter) as working electrode, a platinum plate as counter electrode and $\mathrm{Ag}_{(\mathrm{s})} / \mathrm{AgCl}_{(\mathrm{s})} / \mathrm{Cl}^{-}{ }_{(\text {aq })}$ (saturated $\mathrm{KCl}$ ) as reference electrode, and a nitrogen gas bubbler. A Hanna HI $2221 \mathrm{pH}$ meter equipped with a glass combined electrode was used to adjust the $\mathrm{pH}$ values. The functionalization of the MWCNT was verified by FTIR using a spectrophotometer model IRAffinity (Shimadzu). Morphological images of GCE modified with MWCNT (GCE/MWCNT) and with MWCNT-f (GCE/MWCNT-f) were obtained by SEM using a microscope model FESEM; FEG-Quanta-450 (FEI, The Netherlands).

Functionalization of the MWCNT.-The MWCNT were submitted to an oxidative treatment adapted from the method used by Moraes et al. ${ }^{31}$ which consisted of adding $50 \mathrm{mg}$ of MWCNT to $40 \mathrm{~mL}$ of a mixture of concentrated sulfuric and nitric acids $3: 1(\mathrm{v} / \mathrm{v})$, and keeping the system under stirring for $12 \mathrm{~h}$ at room temperature to obtain a homogeneous suspension. After this, the suspension was filtered through a $0.45 \mu \mathrm{m}$ cellulose acetate membrane (Millipore), the solid was washed with ultrapure water until neutral $\mathrm{pH}$ and then it was dried at $65^{\circ} \mathrm{C}$ for $12 \mathrm{~h}$.

Preparation and characterization of the modified electrodes.Before any surface modification, the GCE was polished with alumina $(0.05 \mu \mathrm{m})$, washed with deionized water, immersed in an ultrasonic bath with ethanol for 10 minutes and rinsed again with deionized water before use. Then, the nanomaterials were deposited on the surface of the GCE by drop-coating; the method consisted of adding $18 \mu \mathrm{L}$ of an<smiles>O=[N+]([O-])/N=C1\NCCN1Cc1ccc(Cl)nc1</smiles>

Figure 1. Chemical structure of imidacloprid. ethanol suspension containing $1.0 \mathrm{mg} / \mathrm{mL}$ of MWCNT or MWCNT-f to the surface of the GCE and allowing the solvent to evaporate at ambient temperature. Subsequently, the resulting modified electrodes were subjected to successive potential cycling in $0.10 \mathrm{~mol} \mathrm{~L}^{-1} \mathrm{KCl}$ solution, between -1.2 and $1.0 \mathrm{~V}$ at a scan rate $(\nu)$ of $25 \mathrm{mV} \mathrm{s}^{-1}$, until a constant voltammetric profile was obtained.

The electrochemical characterization of the modified electrodes was carried out by comparing the CV profiles of the bare GCE with the GCE/MWCNT and GCE/MWCNT-f in $0.10 \mathrm{~mol} \mathrm{~L}^{-1} \mathrm{KCl}$ supporting electrolyte, after deaeration with $\mathrm{N}_{2}$ gas $(99.999 \%)$ for $15 \mathrm{~min}$; the cyclic voltammograms were recorded at $25 \mathrm{mV} \mathrm{s}^{-1}$.

Electroanalytical procedure.-The redox behavior of the IMC $\left(9.8 \times 10^{-5} \mathrm{~mol} \mathrm{~L}^{-1}\right)$ was firstly evaluated on GCE, GCE/MWCNT and GCE/MWCNT-f in $0.10 \mathrm{~mol} \mathrm{~L}^{-1} \mathrm{KCl}, \mathrm{pH} 7.0$, by CV at $25 \mathrm{mV}$ $\mathrm{s}^{-1}$. The best working electrode for electroanalysis of IMC was selected based on the highest sensitivity and on the most reproducible signal. Then, the effect of the electrolyte $\mathrm{pH}$ on the IMC current was tested $(4.0-9.0)$ and the best condition was defined to evaluate the influence of the scan rate $\left(10-200 \mathrm{mV} \mathrm{s}^{-1}\right)$ on the peak intensity and voltammetric profile. Finally, the analytical curves were performed by successive additions of $1.2 \times 10^{-4} \mathrm{~mol} \mathrm{~L}^{-1}$ IMC in supporting electrolyte of $0.1 \mathrm{~mol} \mathrm{~L}^{-1} \mathrm{KCl}$ at $\mathrm{pH}$ 7.0. All experiments were carried out with solutions previously deaerated with high-purity $\mathrm{N}_{2}$ gas for $15 \mathrm{~min}$, and before each cyclic sweep, the medium was stirred with a stream of $\mathrm{N}_{2}$ gas bubbled in the solution for $3 \mathrm{~min}$.

The detection (LOD) and quantification limits (LOQ) were estimated by the quotient between the standard deviation of the intercepts and the average of the slopes, obtained from the linear regression equations of analytical curves. ${ }^{32}$ Repeatability and reproducibility of the sensor were evaluated by means of the RSD of the average of the peak currents, referring to three measurements, obtained with a IMC standard solution of concentration $1.77 \times 10^{-6} \mathrm{~mol} \mathrm{~L}^{-1}$; repeatability was assessed for successive measurements using a single GCE/MWCNT-f sensor and reproducibility using three replicates of this sensor, prepared under the same conditions.

River water sampling.-Water samples were collected from Rio do Carmo near the areas of melon, bean and corn cultivation in the state of Rio Grande do Norte, a semi-arid region of Brazil. The water samples were collected in amber glass flasks, filtered on qualitative filter paper and kept under refrigeration at $4{ }^{\circ} \mathrm{C}$ until electroanalysis (maximum of 3 days). These samples were used without dilution and artificially contaminated with the pesticide to evaluate the applicability of the method.

Application.-To evaluate the applicability and accuracy of the proposed methodology, IMC recovery assays were performed in 


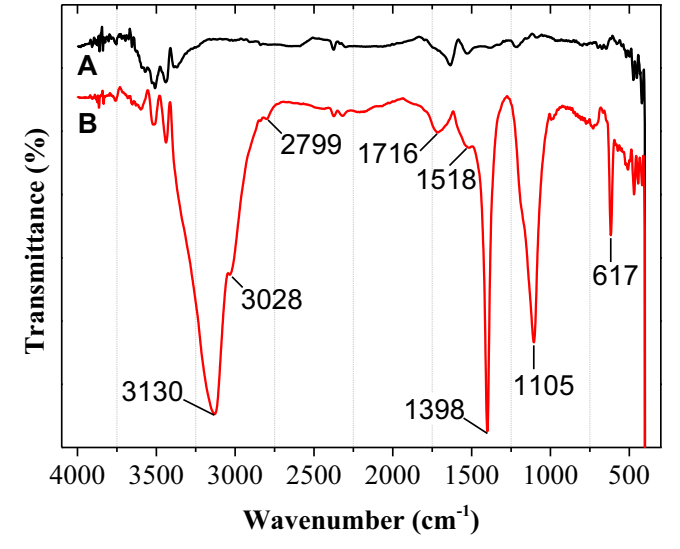

Figure 2. FTIR spectra of the (A) MWCNT and (B) MWCNT- $f$ powder samples.

spiked river water samples at $7.16 \times 10^{-7}$ to $1.19 \times 10^{-6} \mathrm{~mol} \mathrm{~L}^{-1}$. All experiments were taken at $25^{\circ} \mathrm{C}$ and the results were presented as the average of at least three measurements.

\section{Results and Discussion}

Structural characterization of MWCNT and MWCNT-f powder samples.-To confirm that the functionalization process occurred, the infrared spectra (Figure 2) of the MWCNT (a) and MWCNT-f (b) were recorded in the range 400 to $4000 \mathrm{~cm}^{-1}$. It should be noted that there are significant differences between the spectra of the MWCNT samples before and after the acid treatment. Figure $2 \mathrm{~b}$ shows stretching vibration characteristic peaks of MWCNT-f at $3130 \mathrm{~cm}^{-1}(\mathrm{O}-\mathrm{H})$, 3038 and $2825 \mathrm{~cm}^{-1}(\mathrm{C}-\mathrm{H}), 1689 \mathrm{~cm}^{-1}, 1538 \mathrm{~cm}^{-1}$ and $1398 \mathrm{~cm}^{-1}$ related to $\mathrm{C}=\mathrm{O},-\mathrm{COO}-$, and $-\mathrm{COOH}$, respectively, and $1105(\mathrm{C}-\mathrm{O})$. The hydroxyl, carboxyl and carbonyl functional groups provide a large number of chemical adsorption sites and thus may increase the adsorption capacity of MWCNT-f. The peak at $617 \mathrm{~cm}^{-1}(\mathrm{C}=\mathrm{C})$ can be related to the CNT graphene structure with $\mathrm{sp}^{2}$-bond carbon. In fact, these observations suggested that MWCNT functionalization was successful. ${ }^{33,34}$

Morphological characterization of GCE/MWCNT and $\boldsymbol{G C E} / \boldsymbol{M W C N T}$-f.-Figure 3 displays the SEM micrographs of the MWCNT and MWCNT-f modified GCE. The characteristic morphology of the MWCNT was observed before and after functionalization. ${ }^{35-37}$ An uneven distribution of MWCNT, with formation of some agglomerates on the GCE can be observed (Figure $3 a$ ), while the SEM image of GCE/MWCNT-f (Figure 3b) shows a more homogeneous distribution, nanotubes with smaller lengths and less degree of entanglement, what was attributed to MWCNT functionalization. ${ }^{29-31}$ The chemical modification of the MWCNT structure, through oxidative treatment in strong acids, promoted the incorporation of carboxyl groups and other related functional groups on the surface of the nanomaterials, increasing their solubility and facilitating their dispersion in the solvent. Khani and Moradi ${ }^{38}$ studied the influence of surface oxidation on the morphological and crystallographic structure of MWCNT using different oxidants and found that, after the treatment with acids, a clear change occurred in the diameter of the MWCNT, which was reduced, and in the roughness of the surface along the walls of the tubes. Therefore, the lower degree of aggregation in GCE/MWCNT-f was attributed not only to carboxyl groups, but also to shortened nanotube lengths. ${ }^{29-31,35-37}$

Electrochemical behavior of IMC.-Before the GCE modification (Figure 4 -voltammogram a; amplified result in insert), the electroanalytical peak of IMC $\left(9.8 \times 10^{-5} \mathrm{~mol} \mathrm{~L}^{-1}\right)$ at $-1.12 \mathrm{~V}$ was small, large and unsuitable to detect low concentrations of this analyte. The noted cathodic process is derived from the nitro-group irreversible
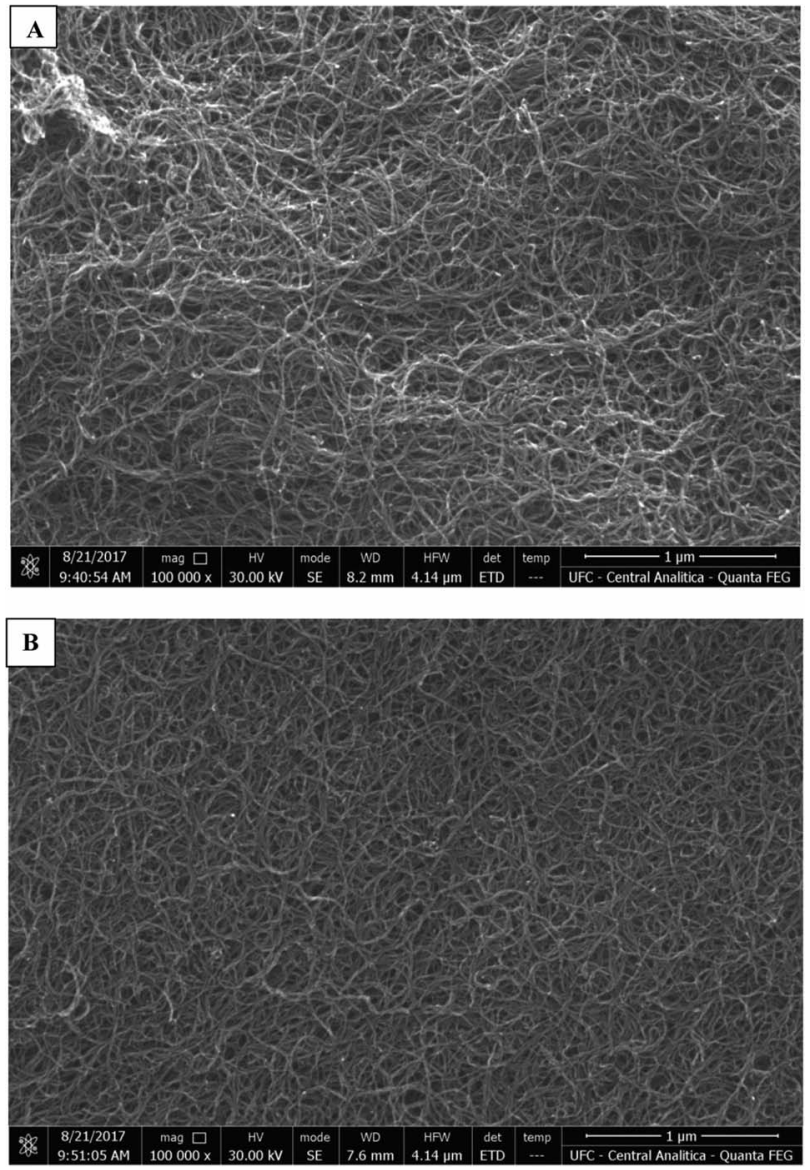

Figure 3. SEM images of (A) GCE/MWCNT and (B) GCE/MWCNT- $f$.

reduction. ${ }^{3,16,18}$ However, after MWCNT (curve b) and MWCNT-f (curve c) immobilization on the GCE surface, a significantly higher (46.4 times for GCE/MWCNT and 51.6 for GCE/MWCNT-f when compared with the GCE response) sharper reduction peak at $-0.98 \mathrm{~V}$ was observed. Also, the peak potential was less negative (about $140 \mathrm{mV}$ ). For both cases, such effects were related with the increase of roughness and active surface area, but on GCE/MWCNT-f these

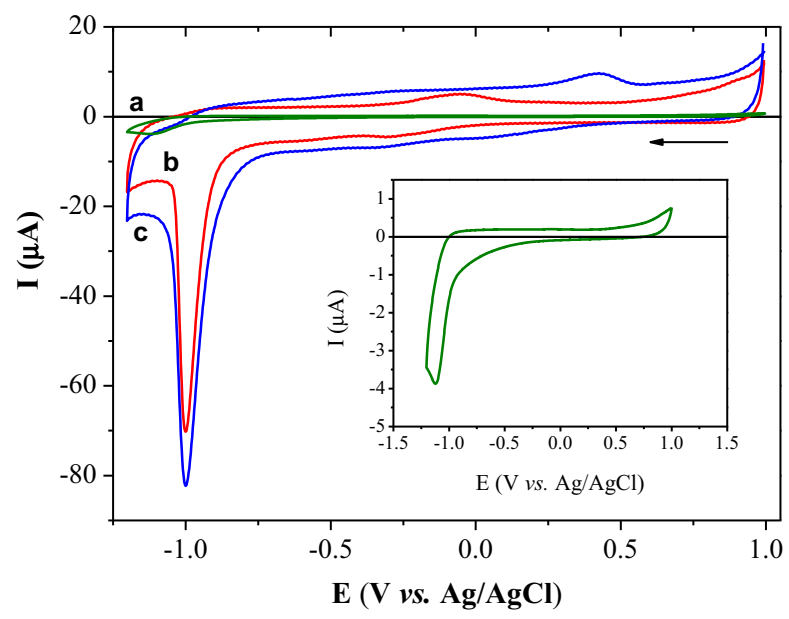

Figure 4. Cyclic voltammograms obtained for $9.8 \times 10^{-5} \mathrm{~mol} \mathrm{~L}^{-1}$ IMC on (a) GCE, (b) GCE/MWCNT and (c) GCE/MWCNT-f at $25 \mathrm{mV} \mathrm{s}^{-1}$ in $0.10 \mathrm{~mol} \mathrm{~L}^{-1} \mathrm{KCl}$ as supporting electrolyte $(\mathrm{pH}=7.0)$. Insert: Amplified cyclic voltammogram for $9.8 \times 10^{-5} \mathrm{~mol} \mathrm{~L}^{-1} \mathrm{IMC}$ on GCE. 


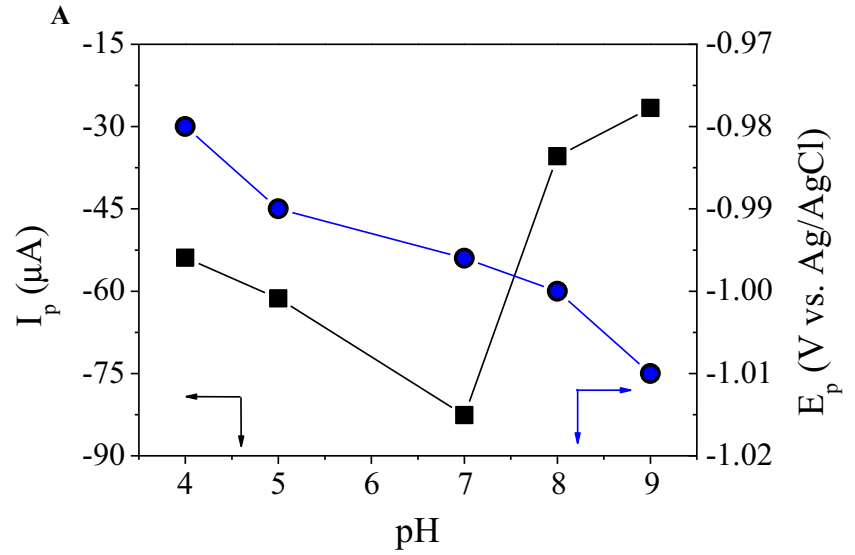

B

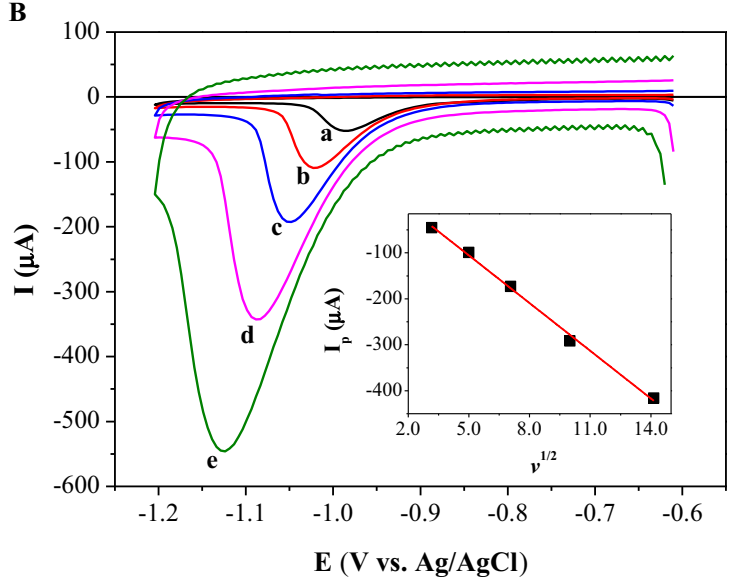

Figure 5. A) Dependence between the reduction peak currents (blue circles) and the potentials (black squares) of $9.8 \times 10^{-5} \mathrm{~mol} \mathrm{~L}^{-1}$ IMC and the $\mathrm{pH}$ on GCE/MWCNT-f using cyclic voltammetry at $25 \mathrm{mV} \mathrm{s}^{-1}$. B) Effect of the scan rate on the IMC peak current at $9.8 \times 10^{-5} \mathrm{~mol} \mathrm{~L}^{-1}$ on GCE/MWCNT-f in $0.10 \mathrm{~mol} \mathrm{~L}^{-1} \mathrm{KCl}(\mathrm{pH}=7.0)$ : (a) $10 \mathrm{mV} \mathrm{s}^{-1}$, (b) $25 \mathrm{mV} \mathrm{s}^{-1}$, (c) $50 \mathrm{mV}$ $\mathrm{s}^{-1}$, (d) $100 \mathrm{mV} \mathrm{s}^{-1}$ and (e) $200 \mathrm{mV} \mathrm{s}^{-1}$. Insert: Relationship between peak current and the square root of scan rate.

phenomena were even more evident possibly due to the contributions of carboxyl groups distributed on basal and edge planes of the MWCNT-f and to the improved electrocatalytic activity and chargetransfer kinetics of the redox events on the working electrode surface. Similar results can be observed in previous reports. ${ }^{2,31,37}$ In addition, functionalization of the carbon nanotubes also increases their solubility and dispersibility in the solvent, allowing to obtain reproducible modiýcations of the working device. Thus, GCE/MWCNT-f was employed in the subsequent studies.

Effect of pH.-The effect of $\mathrm{pH}$ on the electrochemical reduction of IMC $\left(9.8 \times 10^{-5} \mathrm{~mol} \mathrm{~L}^{-1}\right)$ on GCE/MWCNT-f was evaluated in the range from 3.0 to 9.0. The peak potential $\left(E_{p}\right)$ had only non significant and non-linear displacements toward more negative regions, but the peak current $\left(I_{p}\right)$ was strongly affected. The $I_{p}$ values increased considerably when the $\mathrm{pH}$ ranged from 3.0 to 7.0 (Figure 5A), but decreased at higher $\mathrm{pH}$ because the probable hydrolysis of IMC nitroguanidine functional group in alkaline medium. ${ }^{39} \mathrm{In}$ order to maximize the sensitivity of IMC electroanalysis, $\mathrm{pH}=7.0$ was selected as optimum.

Effect of scan rate.- Since the scan rate affects the reversibility and mass transport of the analyte on the electrolyte/electrode interface, its influence on the IMC peak was assessed in the range of $10-$ $200 \mathrm{mV} \mathrm{s}^{-1}$. As can be seen (Figure 5B), the increase of the scan rate provided displacements of $E_{p}$ values toward more negative values,

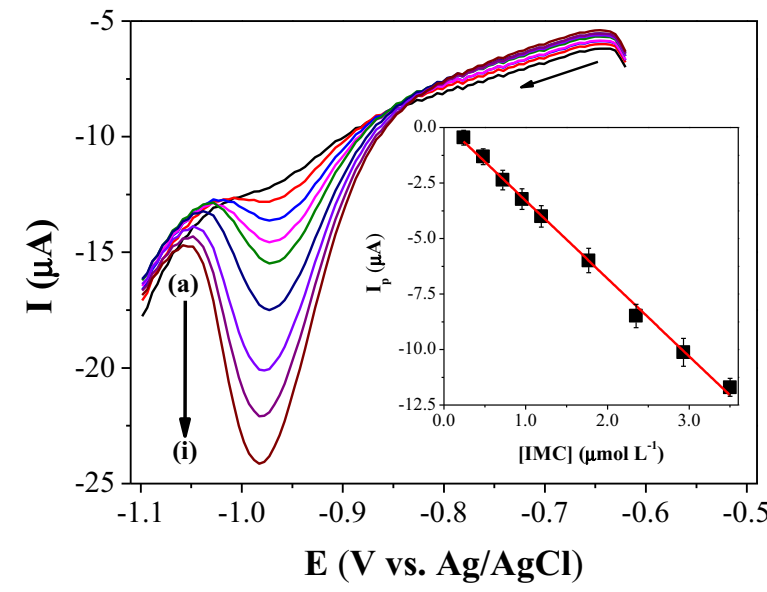

Figure 6. Linear sweep voltammograms for successive standard additions of $1.2 \times 10^{-4} \mathrm{~mol} \mathrm{~L}^{-1} \mathrm{~mol} \mathrm{~L}^{-1} \mathrm{IMC}$ in $0.10 \mathrm{~mol} \mathrm{~L}^{-1} \mathrm{KCl}$ at $\mathrm{pH} 7.0$ on GCE/MWCNT- $f$ at $25 \mathrm{mV} \mathrm{s}^{-1}$. Insert: Corresponding average $(\mathrm{n}=3)$ analytical curve derived from the referred voltammetric data.

which is a characteristic behavior of irreversible redox processes. ${ }^{40}$ According to Laviron's theory, ${ }^{41}$ the relationship between $E_{p}$ and $v$ is described by the following Equation 1:

$$
\begin{aligned}
E_{p}(V)= & E^{o}+(2.303 R T \mid \alpha n F) \log \left(R T k_{s} \mid \alpha n F\right) \\
& +(2.303 R T \mid \alpha n F) \log \nu
\end{aligned}
$$

where $\alpha$ is the charge-transfer coefficient, $k_{s}$ is the heterogeneous rate constant of the reaction, $n$ is the number of electron transferred, and the other constants have their usual meanings. The theoretical $\alpha n$ value, 0.553 , was calculated from the slope of $E_{p}$ vs. $\log v$. Considering $\alpha=0.5$, a typical value for electron transfer involving organic compounds, ${ }^{42}$ it can be concluded that the IMC reduction reaction on GCE/MWCNT-f involved a transfer of one electron in the ratedetermining step. This result corroborated that reported by Majidi, Baj and Bamorowat, ${ }^{22}$ who used an ionic liquid modified carbon-ceramic electrode for the determination of IMC in agricultural products. A linear relationship between $I_{p}$ and $v^{1 / 2}$ (inset of Figure $5 \mathrm{~B} ; \mathrm{n}=3$; $R^{2}=0.998$ ) was also observed, which indicated a diffusion controlled process for the IMC reduction on GCE/MWCNT-f.

Electroanalysis of IMC.-Figure 6 shows the cyclic voltammograms obtained for the reduction of IMC at different concentrations under optimum experimental conditions. The $i_{p}$ increased linearly with IMC concentrations (inset in Fig. 6) over the range from 2.40 $\times 10^{-7}$ to $3.50 \times 10^{-6} \mathrm{~mol} \mathrm{~L}-1$; a linear least squares fit of the data yielded a linear correlation coefficient of 0.997 and a linear regression according to Equation 2:

$$
\begin{aligned}
\mathrm{I}_{\mathrm{p}}(\mu \mathrm{A})= & 2,14 \times 10^{-7}\left( \pm 5,9506 \times 10^{-8} ?\right. \\
& -3,5089( \pm 0,1358)[\mathrm{IMC}]\left(\mu \mathrm{mol} L^{-1}\right)
\end{aligned}
$$

The LOD and LOQ values were calculated to be $4.1 \times 10^{-7} \mathrm{~mol}$ $\mathrm{L}^{-1}$ and $1.4 \times 10^{-6} \mathrm{~mol} \mathrm{~L}^{-1}$, respectively. ${ }^{32}$ These results compare favorably with most of those reported in the literature ${ }^{15-19,21-23,43}$ (Table I), using different electrochemical techniques and in most of the studies more complex sensors, and confirm the sensitivity of the simple proposed approach. In Brazil, there is still no legislation that establishes a maximum limit for residues of this pesticide in river waters. However, the LOD achieved is below the dosage required to cause deleterious effects in different insects, crustaceans and humans. ${ }^{44-46}$

In order to evaluate if the difference between the interception obtained in the analytical curves and the standard values were originated of random errors, the t-test was performed. The value of $t$ calculated was 6.229 , being lower than the critical value (6.965) at the $99 \%$ conýdence level, indicating that there was no signiýcant difference 
between the calculated mean value and the expected standard value. The confidence intervals (CI) described in Eq. 2, for intercept and slope, were calculated according to Equation 3:

$$
\mathrm{CI}=\overline{[\mathrm{IMC}]} \pm\left(\mathrm{t}_{\mathrm{n}-1}\right) \frac{s}{\sqrt{n}}
$$

where [IMC] is the IMC concentration, $t_{n-1}$ is the calculated t-value and the other symbols are similar to those used in the t-test.

Repeatability and reproducibility of the voltammetric response were also estimated from three measurements obtained with $1.77 \times$ $10^{-6} \mathrm{~mol} \mathrm{~L}^{-1} \mathrm{IMC}$ standard solution. The calculated RSD values were $1.1 \%$ (a single sensor) and 6.8\% (three different sensors), respectively, and meet the evaluation criteria of analysis methods, for the low concentrations used in this work. ${ }^{47}$ Thus, the GCE/MWCNT-f sensor can be used for practical applications, such as the determination of IMC in complex environmental samples such as river waters.

Application of the procedure in river water samples.-The analytical procedure presented above was applied to fortified samples of waters collected from the Carmo River that is influenced by agricultural activities carried out in its surroundings (mainly melon cultivation). The selected water samples are representative of complex aquatic environments that have high concentration of dissolved organic matter (total organic carbon, TOC $=428 \mathrm{mg} \mathrm{L}^{-1}$ and chlorophyll $=53 \mu \mathrm{g} \mathrm{L}^{-1}$ ).

The attained recovery values ranged from $90-95 \%$ demonstrating the accuracy and the precision of the developed methodology for quantification of IMC in complex environmental samples, without any previous extraction step.

\section{Conclusions}

This work concerned the development of a simple methodology for determination of the IMC insecticide in natural waters, using a glassy carbon electrode modified with functionalized carbon nanotubes. The presence of MWCNT and MWCNT-f on the surface of the GCE contributed positively to the electron transfer kinetics, allowing an increase of the surface area, the intensity of the IMC reduction process and the sensitivity of the proposed method. The electroanalytical method also showed precision between the measurements (RSD of $1.1 \%$ and $6.8 \%$ for repeatability and reproducibility, respectively) and allowed the analysis of IMC in real samples (river water). Thus, the GCE/MWCNT-f sensor can be a promising tool for the analysis and monitoring of IMC in complex environmental matrices.

\section{Acknowledgments}

The authors thank the Brazilian research funding institutions CNPq (through the projects CNPq-PVE 2014, Proc. 400223/20147 and 303596/2014-7) CAPES and FINEP for their financial support. The authors also are grateful to the Central Analítica - UFC/CTINFRA/MCTI-SISNANO/Pró-Equipamentos CAPES for technical support.

\section{ORCID}

Suely Souza Leal Castro (1) https://orcid.org/0000-0002-5299-8592

\section{References}

1. A. K. Srivastava, M. K. Srivastava, D. K. Patel, M. K. R. Mudiam, and L. P. Srivastava, Journal of Environmental Research and Development, 7(2), 643 (2012).

2. T. M. B. F. Oliveira, M. F. Barroso, S. Morais, P. de Lima-Neto, A. N. Correia, M. B. P. P. Oliveira, and C. Delerue-Matos, Talanta, 106, 137 (2013).
3. L. Zhao, J. Yang, H. Ye, F. Zhao, and B. Zeng, RSC Advances, 7, 4704 (2017).

4. S. Mostafalou and M. Abdollahi, Toxicol. Appl. Pharmacol., 268, 157 (2013).

5. L. M. Silva, R. P. A. dos Santos, C. C. O. Morais, C. L. Vasconcelos, C. A. Martínez-Huitle, and S. S. L. Castro, Journal of The Electrochemical Society, 164(13), E489 (2017).

6. P. Jeschke, R. Nauen, M. Schindler, and A. Elbert, J. Agric. Food Chem., 59, 2897 (2011).

7. TDC Environmental. Insecticide market trends and potential water quality implications, TDC Environmental, LLC, San Mateo, CA, USA (2003).

8. A. D. Muccio, P. Fidente, D. A. Barbini, R. Dommarco, S. Seccia, and P. Morrica, $J$ Chromatogr. A, 1108, 1 (2006).

9. L. Chen and B. Li, J. Chromatogr. B, 897, 32 (2012).

10. A-Y. Ko, M. M. Rahman, A. Abd El-Aty, J. Jang, J-H. Park, S-K. Cho, and J-H. Shim, Food Chem., 148, 402 (2014).

11. J. L. Flores, A. M. Díaz, and M. F. de Córdova, Talanta, 72, 991 (2007).

12. E. Watanabe, K. Baba, H. Eun, and S. Miyake, Food Chem., 102, 745 (2007).

13. G. Quintás, S. Armenta, S. Garrigues, and M. de la Guardia, J. Braz. Chem. Soc., 15, 307 (2004).

14. X. Zhang, Z. Sun, Z. Cui, and H. Li, Sens. Actuators B, 191, 313 (2014).

15. G.-D. Jin and X.-Y. Hu, Chinese Journal of Analysis Laboratory, 4, 14 (2008).

16. Z. Papp, I. Švancara, V. Guzsvány, K. Vytřas, and F. Gaál, Microchimica Acta, 166 , 169 (2009).

17. M. R. Majidi, K. Asadpour-Zeynali, M. Bamorowat, and M. Nazarpur, Journal of the Chinese Chemical Society, 58, 207 (2011).

18. M. Chen, Y. Meng, W. Zhang, J. Zhou, J. Xie, and G. Diao, Electrochimica Acta, 108(1), 1 (2013).

19. J. Liu, Y. Li, G. Song, K. Zhang, and B. Ye, International Journal of Environmental Analytical Chemistry, 94, 884 (2014).

20. N. Lezi and A. Economou, Electroanalysis, 27, 2313 (2015).

21. M. B. Brahim, H. B. Ammar, R. Abdelhédi, and Y. Samet, Chinese Chemical Letters, 27, 666 (2016).

22. M. R. Majidi, R. F. B. Baj, and M. Bamorowat, Measurement, 93, 29 (2016).

23. M. R. Majidi and S. Ghaderi, Journal of Electroanalytical Chemistry, 792, 46 (2017).

24. N. R. Stradiotto, H. Yamanaka, and M. V. B. Zanoni, J. Braz. Chem. Soc., 14(2), 159 (2003).

25. J. R. Windmiller and J. Wang, Electroanalysis, 25(1), 29 (2013).

26. C. Li, E. T. Thostenson, and T. W. Chou, Composites Science and Technology, 68 1227 (2008).

27. B. Marinho, M. Ghislandi, E. Tkalya, C. E. Koning, and G. De With, Powder Technology, 221, 351 (2012).

28. A. T. Masheter, P. Abiman, G. G. Wildgoose, E. Wong, L. XIAO, N. V. Rees, R. Taylor, G. A. Attard, R. Baron, A. Crossley, J. H. Jones, and R. G. Compton, Journal of Materials Chemistry, 17, 2616 (2007).

29. Y.-T. Shieh, T.-Y. Yu, T.-L. Wang, C.-H. Yang, and W.-T. Liao, Colloid and Polymer Science, 290, 1 (2012).

30. Y.-T. Shieh, G.-L. Liu, H.-H. Wu, and C.-C. Lee, Carbon, 45, 1880 (2007).

31. F. C. Moraes, M. F. Cabral, L. H. Mascaro, and S. A. S. Machado, Surface Science, 605, 435 (2011).

32. ANVISA (Agência Nacional de Vigilância Sanitária, Brazil). RESOLUÇÃO $\mathrm{N}^{\circ}$ 899, de 29 de Maio de 2003. Available in: http://www.asfconsultoria. com.br/normas/ANVISA5.pdf. Access in April 9, 2017.

33. H. Pourzamani, Y. Hajizadeh, and S. Fadaei, Int. J. Environ. Health Eng., 4(2), 29 (2015).

34. B. V. Farahani, G. R. Behbahani, and N. Javadi, J. Braz. Chem. Soc., 27(4), 694 (2016).

35. Z. Zhao, Z. Yang, Y. Hu, J. Li, and X. Fan, Applied Surface Science, 276, 476 (2013).

36. G.-W. Lee, J. Kim, J. Yoon, J.-S. Bae, B. C. Shin, I. S. Kim, W. Oh, and M. Ree, Thin Solid Films, 516, 5781 (2008).

37. A. Benvidi, N. Rajabzadeh, M. Mazloum-Ardakani, and M. M. Heidari, Sensors and Actuators B, 207, 673 (2015)

38. H. Khani and O. Moradi, J. Nanostruct. Chem., 3, 73 (2013).

39. W. Zheng and W. Liu, Pesticide Science, 55, 482 (1999).

40. A. J. Bard and L. R. Faulkner, Electrochemical Methods: Fundamentals and Applications, 2nd ed., John Wiley \& Sons, Inc., New York (2000).

41. E. Laviron, Journal of Electroanalytical Chemistry and Interfacial Electrochemistry, 101, 19 (1979).

42. J. Grimshaw, Electrochemical Reactions and Mechanisms in Organic Chemistry, Elsevier, New York (2000).

43. V. J. Guzsvány, F. F. Gaá, L. J. Bjelica, and S. N. Okresz, J. Serb. Chem. Soc., 70, 735 (2005).

44. C. E. Smit, "Water quality standards for imidacloprid." Proposal for an update according to the Water Framework Directive. RIVM letter report 270006001 (2014).

45. I. Roessink, L. B. Merga, H. J. Zweers, and P. J. Van den Brink, Environ. Toxicol. Chem., 32, 1096 (2013).

46. R. Ashauer, A. Hintermeister, E. Potthoff, and B. I. Eschera, Aquat. Toxicol., 103, 38 (2011).

47. Guidelines for Standard Method Performance Requirements (2016). Official Methods of Analysis, Appendix F, AOAC International, Gaithersburg, MD. 